IT was demonstrated previously that mice undergoing an inflammatory reaction induced by subcutaneous (SC) implantation of copper rods, produce humoral factors that initially enhance, but subsequently inhibit, diffusion chamber (DC) granulopoiesis. This provided evidence that granulopoiesis is under the control of both humoral stimulators and inhibitors. In order to test the granulopoietic regulatory mechanism in leukaemic mice, we investigated the regulatory role of granulopoietic humoral inhibitors during in vivo granulopoiesis. We noticed that mice suffering from acute myeloid leukaemia (AML) are unable to augment the production of these humoral inhibitory factors when acute inflammation is induced, since no change in DC cell content was observed with or without prior inflammation. Moreover, unlike healthy mice, the serum of leukaemic mice withdrawn during the inhibition phase of acute inflammation did not show any inhibitory activity toward granulocyte-monocyte (GM) colony growth in vitro. Our results also show that increased levels of normal humoral inhibitors do not influence the proliferation and/or differentiation of leukaemic cells implanted in diffusion chamber cultures.

Key words: Acute inflammation, Acute myeloid leukaemia (AML), Diffusion chamber (DC), Granulopoiesis, Humoral granulopoietic inhibitor

\section{Granulopoiesis inhibition in acute inflammation: comparative studies in healthy and leukaemic mice}

\author{
Mohamad Hamood, ${ }^{1, C A}$ Francis Corazza, \\ Pierre Francois Bluche, ${ }^{1}$ Hassan El Teraifi, ${ }^{2}$ \\ and Pierre Fondu ${ }^{1}$ \\ ${ }^{1}$ Experimental Hematology Laboratories of \\ Brugmann University Hospital and Joseph \\ Bracops Hospital, Free University of Brussels, \\ Place Van Gehuchten 4, 1020 Brussels, Belgium; \\ ${ }^{2}$ Department of Histopathology, Christie \\ Hospital, Manchester, UK \\ CA Corresponding Author
}

\section{Introduction}

Control of in vivo granulopoiesis by humoral factors is difficult to study for several reasons. Among these reasons are the lack of a satisfactory label for newly released granulocytes, and the emptying of important intramedullary storage pools by injection of foreign proteins. For these reasons, several investigators have used the in vivo intraperitoneal diffusion chamber (DC) culture technique. ${ }^{1}$ This technique allows proliferation and differentiation of nearly all types of haemopoietic cells, and shows that in vivo haemopoietic cell proliferation and differentiation are under the control of humoral regulators. ${ }^{1}$ Under states of increased demand, such as acute inflammation, DC granulopoiesis was regulated by both granulopoietic humoral stimulators and inhibitors. ${ }^{2}$ When DCs, loaded with a constant number of murine bone marrow cells, are implanted into mice that were stimulated the previous day by an aseptic abscess, significantly more proliferative and non-proliferative granulocytes, as well as their progenitors, develop in DC. However, when DCs are implanted 6 days after the induction of acute inflammation, a significant depression of DC granulopoiesis is observed. $^{2}$ This suggests that the release of both humoral granulopoietic stimulators and inhibitors occurs consecutively.

The physiological granulopoietic regulatory mechanism in states of increased demand is not clear in leukaemic subjects, and the failure of normal granulopoiesis in leukaemic hosts is not well understood. However, recent investigations ${ }^{3}$ showed that leukaemic mice are unable to overproduce humoral granulopoietic stimulators during the stimulation phase of acute inflammation. The increased levels of these stimulators do not influence either the proliferation or the differentiation of leukaemic cells implanted in DC.

In the present study we investigated the inflammatory response of leukaemic mice during the inhibition phase of acute inflammation, in order to examine the ability of the leukaemic host to produce physiological granulopoietic inhibitors. In addition, we examined the effect of normal humoral granulopoietic inhibitors on leukaemic cell differentiation and proliferation.

\section{Materials and Methods}

Mice: Male $\mathrm{CBA} / \mathrm{H}$ mice (Centre d'animaux de laboratoire, Heverlee, Belgium) 16-18 weeks of age, 
were used as host animals for the diffusion chamber cultures and as a source for adult normal and leukaemic bone marrow cells.

Induction of acute inflammation: Acute inflammation followed by an aseptic abscess formation was induced by subcutaneous insertion of metallic copper rods under sterile conditions as previously described. ${ }^{2}$ A surgical incision was made in the left paravertebral area in control mice (sham operation) to exclude non-specific effects of surgery on haemopoiesis.

Induction of acute myeloid leukaemia ( $A M L)$ : Acute myeloid leukaemic cells were obtained from the spleen of $\mathrm{CBA} / \mathrm{H}$ leukaemic mice (Radiobiology Unit, Harwell, Didcot, Oxon, UK). AML was induced by ionizing radiation ${ }^{4}$ and maintained by serial intravenous inoculation into new $\mathrm{CBA} / \mathrm{H}$ mice as previously described. ${ }^{5}$ Each host $\mathrm{CBA} / \mathrm{H}$ mouse was injected intravenously with $0.2 \mathrm{ml}$ of suspension medium containing one million leukaemic splenic cells, 8 days prior to copper insertion. The suspension medium was Hanks's Balanced Salt Solution (HBSS) with 10\% fetal calf serum.

Diffusion chamber cultures: DCs were prepared according to Benestad. ${ }^{6}$ Briefly, two DCs were filled with $0.1 \mathrm{ml}$ Alpha Modified Essential Medium ( $\alpha$-MEM) containing $5 \times 10^{5}$ murine bone marrow cells. These DCs were implanted in the peritoneal cavity of each host mouse 6 days after inflammation induction or sham operation, for a 3-day period. Then the DCs were removed and agitated for $1 \mathrm{~h}$ in $\alpha$-MEM containing $5 \%$ Ficoll and $0.5 \%$ pronase to dissolve any fibrin clot. The contents were harvested as described by Tyler $e t a l .^{7}$ Direct smears, differential counts and cell classification were performed as previously described. ${ }^{8}$

In the first part of the experiment, DCs were loaded with normal bone marrow cells and implanted in healthy and leukaemic mice, both challenged with aseptic abscesses, in order to examine the humoral regulatory system in each group. In the second part of the experiment, DCs loaded with leukaemic cells were implanted in healthy mice alone, with and without aseptic abscesses, in order to examine the leukaemic cell response to humoral regulators.

Assay for colony stimulating activity: Sera obtained from host mice were pooled and assayed for their ability to inhibit the growth of haemopoietic colonies in agar gel. Serum colony inhibitory activity was expressed by the reduction in the mean number of colonies produced by mixing $0.03 \mathrm{ml}$ of tested serum with $0.13 \mathrm{ml}$ horse serum when $10^{5}$ bone marrow cells were seeded. The number of granulocyte monocyte colony forming units (CFU-GM) was determined in agar by a modified version that has been described previously., 90 Pokeweed mitogen-stimulated spleen cell conditioned medium (PWM-SCM) was prepared as previously described, ${ }^{11}$ and added in all experiments to a final concentration of $20 \%$. Colonies were counted on day 5 of culture. Three to five plates were counted for each experimental point.

Statistics: Results are expressed as means \pm standard error of the means (SEM). Mann-Whitney's U test was used to assess the statistical significance between two comparable experimental groups, and the Kruskal-Wallis test was used to assess statistical significance between more than two groups.

\section{Results}

Diffusible granulopoietic inbibitor release in bealthy and leukaemic mice: Normal murine bone marrow cells were cultured in DCs implanted intraperitoneally both in normal and leukaemic hosts 6 days after copper insertion or sham operation. Three days after DC implantation we observed that, in healthy mice, DC cell growth was lower in the copperinserted group than in the sham-operated mice $(104.496 \pm 11.157,167.849 \pm 14.608$, respectively; $p<0.025$, Figure 1). However, DC cell growth rate was not changed in leukaemic hosts with or without copper insertion $(150.983 \pm 11.890,144.246 \pm$ 12.309 , respectively; $p>0.2$, Figure 1$)$. Moreover, the growth rate of DC granulocytes was significantly higher in leukaemic hosts when compared to healthy mice during the inhibition phase of acute inflammation $(p<0.025)$.

Changes in proliferative and non-proliferative granulocytes and in macrophages are shown in

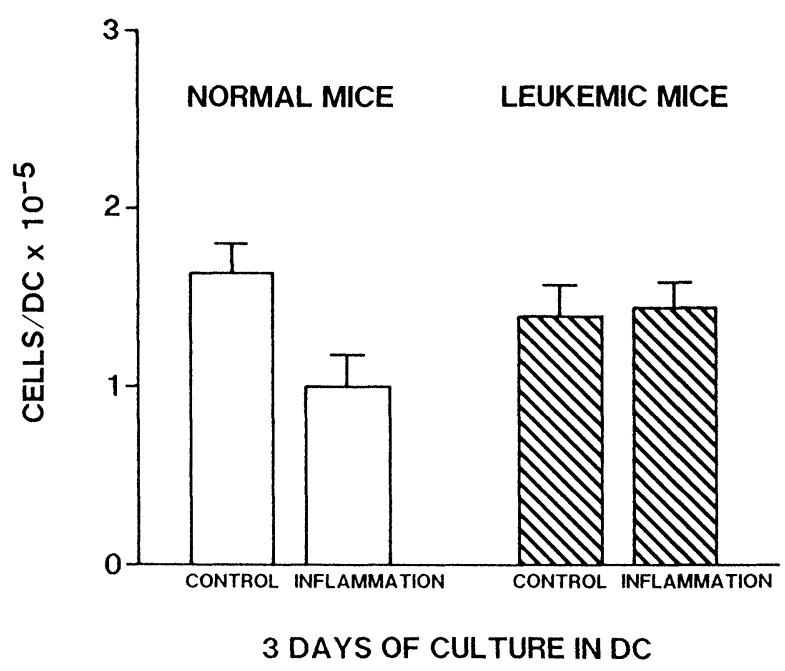

FIG. 1. The effect of acute inflammation inhibition phase on DC granulopoiesis in healthy and leukaemic hosts. Four groups of mice were studied: in each group (minimum three mice) at least six DCs were analysed for each experiment. The results are expressed as mean \pm SEM for three experiments. 
Table 1. The differential growth of normal murine bone marrow cells implanted into diffusion chambers. Cells were harvested on the third day of culture. The results represent mean values \pm SEM from three experiments

\begin{tabular}{lccc}
\hline & \multicolumn{3}{c}{ Granulocyte/DC } \\
\cline { 2 - 4 } \multicolumn{1}{c}{ Host condition } & Proliferative & Non-proliferative & Macrophages \\
\hline Healthy mice & & & \\
Sham-operated controls & $78.829 \pm 7.614$ & $38.216 \pm 4.942$ & $40.837 \pm 6.878$ \\
Copper-inserted mice & $48.842 \pm 4.988$ & $28.480 \pm 3.844$ & $27.342 \pm 4.382$ \\
Leukaemic mice & & & \\
Sham-operated controls & $68.432 \pm 5.882$ & $33.876 \pm 4.128$ & $31.488 \pm 4.672$ \\
Copper-inserted mice & $70.864 \pm 7.134$ & $36.684 \pm 4.855$ & $34.460 \pm 4.825$ \\
\hline
\end{tabular}

Table 1. The production of both proliferative and non-proliferative granulocytes and of macrophages, is lower in DC implanted in copper-inserted healthy mice than in sham-operated controls $(p<0.025)$. However, in leukaemic copper-inserted hosts these numbers remained equal to those observed in sham-operated leukaemic controls $(p>0.2)$. These data indicate that humoral granulopoietic inhibitor release is demonstrable in healthy but not in leukaemic mice.

Serum colony inbibitory activity in bealthy and leukaemic mice: Serum of sham-operated healthy controls permitted in vitro growth of $63 \pm 9$ CFU-GM, while serum of copper-inserted healthy mice during the inhibition phase of acute inflammation ( 6 days after copper insertion) permitted growth of $17 \pm 5$ CFU-GM. This statistically significant difference $(p<0.01)$ indicates that serum of copper-inserted mice contains an inhibitor to in vitro growth of granulocyte monocyte colonies. However, in leukaemic hosts, copper insertion did not change serum levels of inhibitors $(p>0.2$, Table 2$)$.

Leukaemic cell response to humoral inbibitors: AML cells were implanted in DCs in healthy mice during the inhibition phase of acute inflammation. No change in DC leukocyte number was

Table 2. Serum GM-colony growth inhibitor production in healthy and leukaemic mice during the inhibition phase of acute inflammation. Each value represents the mean + SEM for three experiments. The serum was pooled, six days after the induction of inflammation, from five to eight mice in each group. Inhibitory activity was expressed as the mean number of CFU-GM colonies in agar gel.

\begin{tabular}{lc}
\hline \multicolumn{1}{c}{ Host condition } & $\begin{array}{c}\text { CFU-GM } / 10^{5} \text { cultured } \\
\text { bone marrow cells }\end{array}$ \\
\hline Healthy mice & $63 \pm 9$ \\
Sham-operated controls & $17 \pm 5$ \\
Copper-inserted mice & \\
Leukaemic mice & $72 \pm 11$ \\
Sham-operated controls & $74 \pm 12$ \\
Copper-inserted mice & \\
\hline
\end{tabular}

observed compared to the control $(p>0.2$, Figure $2)$. This shows the lack of leukaemic cell response to humoral inhibitors. Moreover, the growth rate of leukaemic cells in DC was significantly higher than the growth rate of normal cells $(p<0.01)$, irrespective of prior inflammation. DC differential cell counts showed no change in maturation state of DC leukaemic cells implanted in copper-inserted mice. The number of blasts in DC implanted in copper-inserted mice was $156.432 \pm 64.384$, while the number of blasts in DC implanted in sham-operated hosts was $155.464 \pm 48.212(p>$ $0.2)$.

\section{Discussion}

The induction of acute inflammation in healthy mice by subcutaneous insertion of sterile metallic copper rods, is associated with myeloid hyperplasia and a significant increase in the levels of serum colony stimulating factors (CSF), as well as an

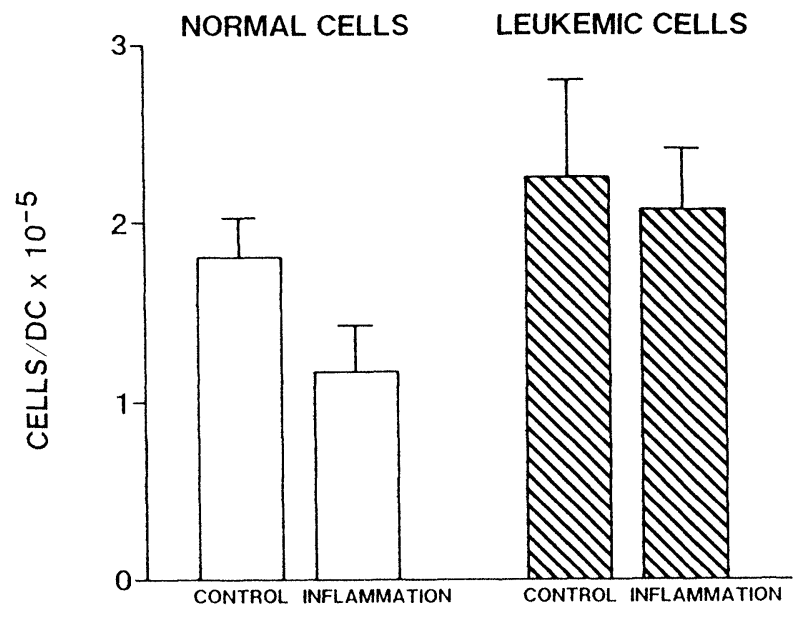

3 DAYS OF CULTURE IN DC

FIG. 2. The effect of acute inflammation inhibition phase on both DC leukaemic and normal cell growth. DCs were implanted in four groups of healthy mice: in each group (minimum three mice) at least six DCs were analysed for each experiment. The results are expressed as mean $\pm S E M$ for three experiments. 
enhancement of DC granulopoiesis. ${ }^{2,12,13}$ However, 6 days after induction of inflammation, the DC-granulopoiesis is inhibited, suggesting that diffusible granulopoietic humoral inhibitors are released, 2,14 and indicating a negative feedback control of in vivo granulopoiesis. Investigating the release of these humoral regulators in a leukaemic host is of special interest, as testing the capability of a leukaemic host to produce these factors might explain, in part, the mechanism of normal granulopoiesis failure in leukaemic subjects. Recent investigations $^{3}$ showed that leukaemic mice are unable to overproduce granulopoietic humoral stimulators during the stimulation phase of acute inflammation.

In this study we examined the humoral response of leukaemic mice during the inhibition phase of acute inflammation. The growth rate of normal DC-granulocytes implanted in leukaemic hosts proceeded to the same limiting concentrations with or without prior inflammation. This suggests that either leukaemic hosts are again unable to overproduce humoral granulopoietic inhibitors, or these inhibitors are functioning in vivo in an improper manner. However, several investigators have shown that leukaemic cells produce inhibitory substances which suppress normal granulopoiesis. ${ }^{15,16}$ The possibility that the level of these inhibitory substances is almost maximum in leukaemic mice has been excluded, as the number of DC cells is even higher in leukaemic mice when compared to healthy mice during the inhibition phase.

In vitro growth of haemopoietic cells is stimulated by a group of glycoproteins, of different molecular weights, called the colony stimulating factors (CSF). ${ }^{17}$ Our previous studies ${ }^{12}$ showed that during the stimulation phase of acute inflammation the level of CSF is significantly high in the serum of normal mice. This is consistent with the increased levels of granulopoietic stimulators that enhance DC granulopoiesis in this phase of acute inflammation. In this study we investigated the presence of granulopoietic colony inhibitors in the serum of the host mice during the inhibition phase of acute inflammation. We observed that the serum of non-leukaemic mice contains inhibitory activity to granulocytic colony growth in vitro. This activity is not demonstrable in the serum of leukaemic mice challenged or non-challenged with inflammation. It is not known yet whether the inhibitory activity in the serum that acts on in vitro granulocytic growth, and the humoral granulopoietic inhibitor that depresses DC-granulocyte number in vivo, represents one or several factors. Their relationship to the previously described in vitro inhibitors, such as lactoferrin, ${ }^{18}$ monocyte prostaglandin, ${ }^{19}$ colony-stimulating activity inhibitors, ${ }^{20}$ and the transforming growth factor beta (TGF- $\beta$ ), ${ }^{21}$ is also unclear. However, both of them are produced in non-leukaemic mice but not in leukaemic ones during the inhibition phase. Recently, we showed that T-lymphocytes are involved in the release of granulopoietic humoral inhibitors, either directly or indirectly, by their interaction with other accessory bone marrow cells. $^{14}$ This raises the question of whether T-lymphocyte functional disorder in AML explains the lack of response in leukaemic mice during the inhibition phase of acute inflammation.

Unlike the growth rate of normal DC cells, the growth rate of leukaemic cells implanted into a non-leukaemic environment is unaffected by the rise in humoral inhibitor levels, as no change is observed in granulocyte cell proliferation and differentiation. The growth rate of leukaemic cells in DC implanted in normal mice, with or without prior inflammation, is significantly higher than the growth of normal cells. This shows that extrinsic physiological inhibitors are unable to reduce the growth rate of murine leukaemic cells, which proliferate irrespective of prior inflammation, reflecting uncontrolled proliferation of the leukaemic cells. These observations support the view that AML is the expression of an intrinsic cellular defect and is consistent with the findings of other investigators. $^{22}$ However, several studies showed that certain growth factors could inhibit leukaemic bone marrow cell growth in vitro, like TGF- $\beta,{ }^{21}$ the leukaemia inhibitory factor, ${ }^{23}$ and the granulocytic chalone. ${ }^{24,25}$ Thus, it may be asked why leukaemic cells respond to in vitro inhibitors and not to in vivo humoral physiological inhibitors, but the answer is not clear.

However, the nature of in vivo inhibitors that have been released after the induction of inflammation, and their relation to the specific purified in vitro growth factors, is not known yet. They might be different regulatory factors, or their concentrations in in vivo normal physiological conditions may be lower than in in vitro exploited concentrations. Moreover, the colony stimulating factor receptor expression by AML blast cells has been shown to be weaker than that caused by the normal mature granulocytes. ${ }^{26,27}$ This weakness in receptor expression could therefore be a possible explanation for the lack of leukaemic cell response to increased or decreased levels of physiological humoral factor regulators after inflammation induction.

Other models of diffusion chamber granulopoiesis enhancement have been investigated in hosts rendered neutropenic with myelotoxic drugs ${ }^{7,28}$ or irradiation. $^{29}$ This has been interpreted as evidence for humoral influence on granulocyte production. Nevertheless, because of the numerous effects of myelotoxic drugs or irradiation, the changes 
leading to increased cell proliferation in DC might be quite nonspecific. Moreover, diffusion chamber granulopoiesis enhancement after endotoxin administration ${ }^{30}$ will modify the host environment and can also affect directly the cellular content of DC. On the other hand, none of these models showed that granulopoiesis regulation in DC is under the influence of both humoral stimulators and inhibitors, as the aseptic abscess model showed. However, our findings are in agreement with a previous study ${ }^{31}$ in which irradiation had been exploited as a stimulus to the growth of normal granulocytic cells in DC, since leukaemic cells proliferate equally well with or without prior host irradiation.

In conclusion, our findings show that leukaemic hosts are unable to respond properly to stimuli to release humoral granulopoietic inhibitors. They also show that leukaemic cells are not sensitive to increased levels of physiological humoral inhibitors, as neither their proliferation nor differentiation is affected.

\section{References}

1. Niskanen E, Chatelain C, Symann M. Diffusion chamber colony-forming unit (CFU-d): a primitive stem cell. Int J Cell Cloning 1989; 7: 330-342.

2. Symann $M$, Anckaert MA, Huybrecht $M$, Ninane J, Canon L, Sokal G. In vivo stimulation and inhibition of granulopoiesis: the effect of an inflammatory reaction on murine diffusion chamber granulopoiesis. $\mathrm{Br}$ Haematol 1982; 15: 89-98.

3. Hamood M, Corazza F, Bluche PF, El-Teraifi H, Fondu P. Acute inflammation effects on in vivo granulopoiesis: comparative studies in healthy and leukaemic mice. In vivo 1992; 6: 45-48.

4. Major IR, Mole RH. Radiation-induced myeloid leukaemia in X-ray irradiated CBA mice. Nature 1978; 272: 455-456.

5. Meldrum RA, Mole RH. Radiation-induced myeloid leukemia in $\mathrm{CBA} / \mathrm{H}$ mice: a non-immunogenic malignant disease in syngeneic mice. $\mathrm{Br} J$ Cancer 1982; 45: 403-412.

6. Benestad HB. Formation of granulocytes and macrophages in diffusion chamber cultures of mouse blood leukocytes. Scand J Hematol 1970; 7 279-288

7. Tyler WS, Niskanen E, Stohlman F Jr, Keane J, Howard D. The effect of neutropenia on myeloid growth and the stem cell in an in vivo culture system. Blood 1972; 40: 634-645.

8. Symann M, Quesenberry P, Fontebuoni A, Howard D, Ryan M, Stohlman F Jr. Fetal hemopoiesis in diffusion chamber culture III. The effect of neutropenia. Blood 1976; 48: 283-291.

9. Bradley TR, Metcalf $D$. The growth of mouse bone marrow cells in vitro. Aus J Exp Biol Med Sci 1966; 44: 287-299.

10. Chatelain C, Hamood M, Debast M, Symann M. Cholinergic enhancemen of megakaryocytopoiesis and granulopoiesis in culture: mediation via T-lymphocytes. Exp Hematology 1989; 17: 1067-1071.

11. Burstein SA, Adamson JW, Thoring DJ, Harker LA. Characteristics of murine megakaryocytic colonies in vitro. Blood 1979; 54: 169-179.

12. Hamood M, Chatelain C, Fondu P, Symann M. In vivo elaboration of CSF in acute inflammation: proportionality to the intensity of the inflammatory stimulus and requirement of T-lymphocytes. Eur I Hematol 1990; 45 $244-249$

13. Hamood M, Fondu P. In vivo regulation of granulocyte production in acute inflammation. Cell Proliferation 1991; 24: 181-190.

14. Hamood M, Fondu P. In vivo inhibition of granulopoiesis in acute inflammation requires T-lymphocyte integrity. Int I Cell Cloning 1991; 9: 134-143.

15. Broxmeyer HE, Jacobsen N, Kurland J, Mendelsohn N, Moore MA. In vitro suppression of normal granulocytic stem cells by inhibitory activity derived from human leukemia cells. J Natl Cancer Inst 1978; 60: 497-511.

16. Logan PM, Shellard J, Buskard N, Levy JG. CAMAL: evidence fo inhibitory role in normal granulopoiesis. Exp Hematol 1989; 17: 1072-1076.

17. Burgess AW, Metcalf D. The nature and action of granulocyte-macrophage colony stimulating factors. Blood 1980; 56: 947-958

18. Broxmeyer HE, Smithyman A, Eger RR, Meyers PA, Desousa M. Identification of lactoferrin as the granulocyte-derived inhibitor of colony-stimulating activity production. J Exp Med 1978; 148: 1052-1067.

19. Pelus LM, Broxmeyer HE, Kurland JI, Moore MAS. Regulation of macrophage and granulocyte proliferation. I Exp Med 1979; 150: 277-292.

20. Verma DS, Spitzer G, Zander AR, Beran M, Dicke KA, McCredie KB. Monocyte-macrophage interaction with putative helper and suppressor T-lymphocyte in colony stimulating activity elaboration. In: Baum SJ, Ledney GD, eds. Experimental Hematology Today New York: Springer-Verlag, 1981; 139-150

21. Sing GK, Keller JR, Ellingsworth LR, Ruscetti FW. Transforming growth factor $\beta$ selectively inhibits normal and leukemic human bone marrow cell growth in vitro. Blood 1988; 72: 1504-1511.

22. Symann $\mathrm{M}$, Rodhain J, Huybrechts $\mathrm{C}$, et al. In vivo studies of a murine myeloblastic leukemia. Nouv Rev Fr Hématol 1980; 22: 63-68.

23. Tomida M, Yamamoto-Yamaguchi $Y$, Hozumi M. Purification of a factor inducing differentiation of mouse myeloid leukemic M1 cells from conditioned medium of mouse fibroblast L929 cells. J Biol Chem 1984; 259: 10978-10982.

24. Rytömaa T, Vilpo J, Levanto A, Jones WA. Effect of granulocytic chalone on acute myeloid leukemia in man. Lancet 1977; 1: 771-774.

25. Foa P, Chillemi F, Lombardi L, Lonati S, Maiolo AT, Polli EE. Inhibitory activity of a synthetic pentapeptide in leukaemic myelopoiesis both in vitro and in vivo in rats. Eur J Haematol 1987; 39: 399-403.

26. Budel LM, Touw IP Delwel R, Clarck SC, Löwenberg B. Interleukin 3 (IL-3) and granulocyte-monocyte colony-stimulating factor receptors on human acute myelocytic leukemia cells and relationship to the proliferative response. Blood 1989; 74: 565-571.

27. Motoji T, Watanabe M, Uzumaki $\mathrm{H}$, et al. Granulocyte colony-stimulating factor (G-CSF) receptors on acute myeloblastic leukemia cells and their relationship with the proliferative response to G-CSF in clonogenic assay. Br J Haematol 1991; 77: 54-59.

28. Niskanen E, Tyler WS, Symann M, Stohlman FJR, Howard D. The effect of neutropenia on the cell cycle of granulocyte precursors in an in vivo culture system. Blood 1974; 43: 23-31.

29. Rothstein G, Hugl EH, Bishop CR, Athens JW, Ashenburger HE. Stimulation of granulopoiesis by a diffusible factor in vivo. J Clin Invest 1971; 50: 2004-2007.

30. Rothstein G, Hugl EH, Chervenick PA, Athens JW, Macfarlane J. Humoral stimulators of granulocyte production. Blood 1973; 41: 73-78.

31. Miller AM, Marmor JB, Page PL, Russell JL, Robinson SH. Unregulated growth of murine leukemic cells and suppression of normal granulocyte growth in diffusion chamber cultures. Blood 1976; 47: 737-745.

ACKNOWLEDGEMENTS. The authors are indebted to M. De Bast and M. Roobaert for their technical assistance and to $C$. Vlietinck for preparation of the manuscript. M. Hamood is a research fellow of the Fonds National Belge de la Recherche Scientifique.

\section{Received 25 February 1992;} accepted 25 March 1992 


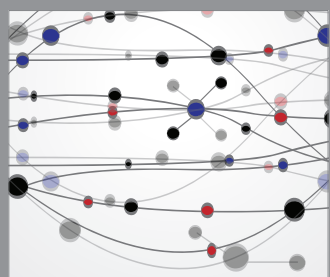

The Scientific World Journal
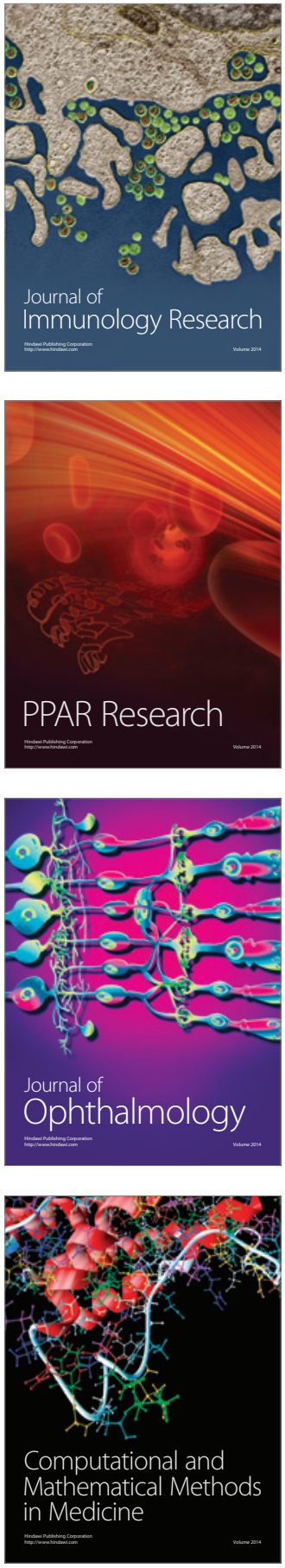

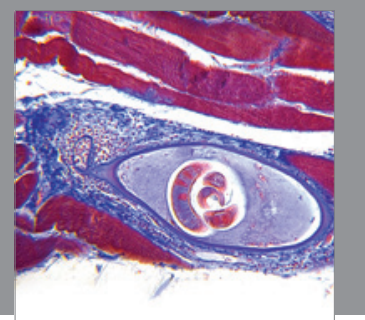

Gastroenterology

Research and Practice
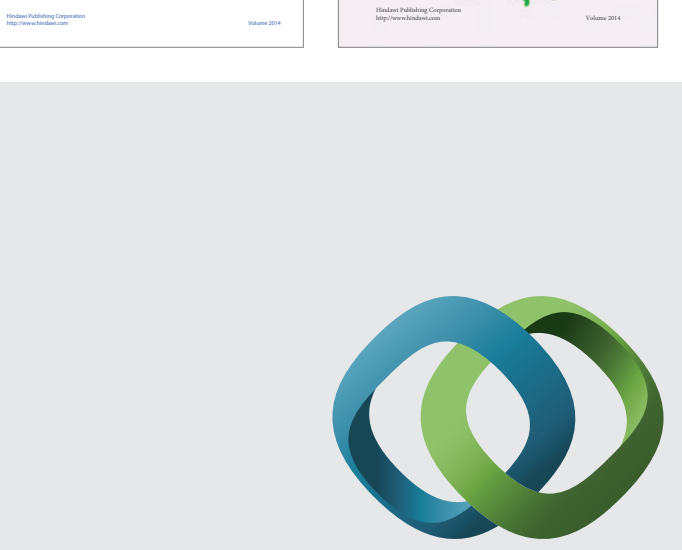

\section{Hindawi}

Submit your manuscripts at

http://www.hindawi.com
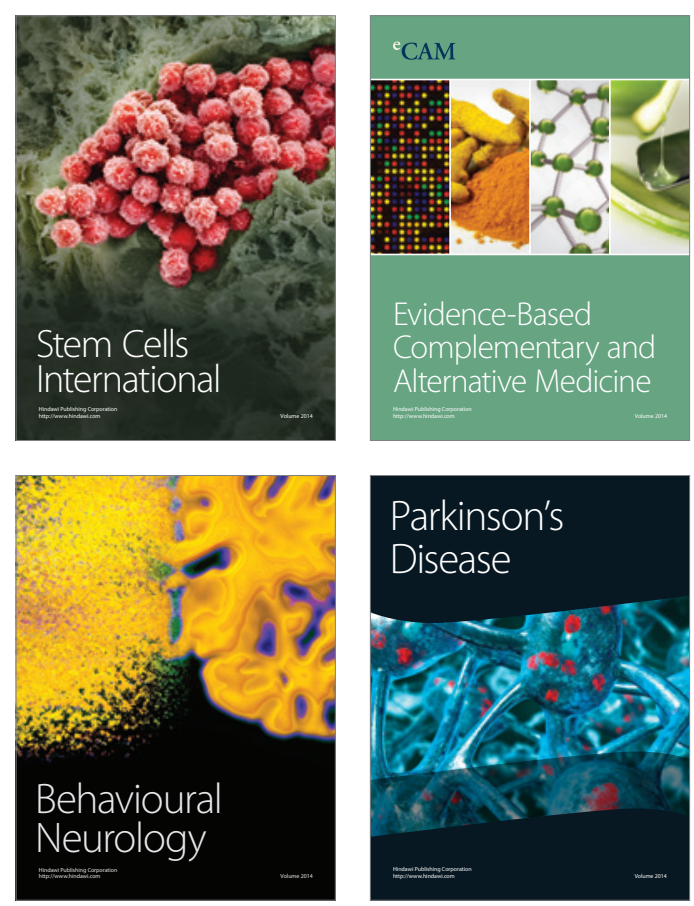

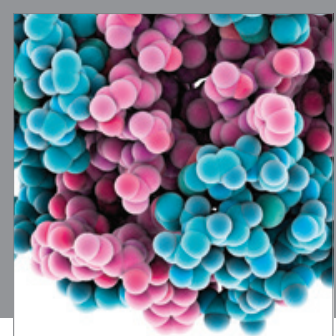

Journal of
Diabetes Research

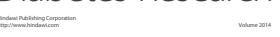

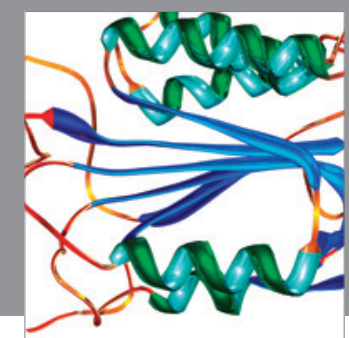

Disease Markers
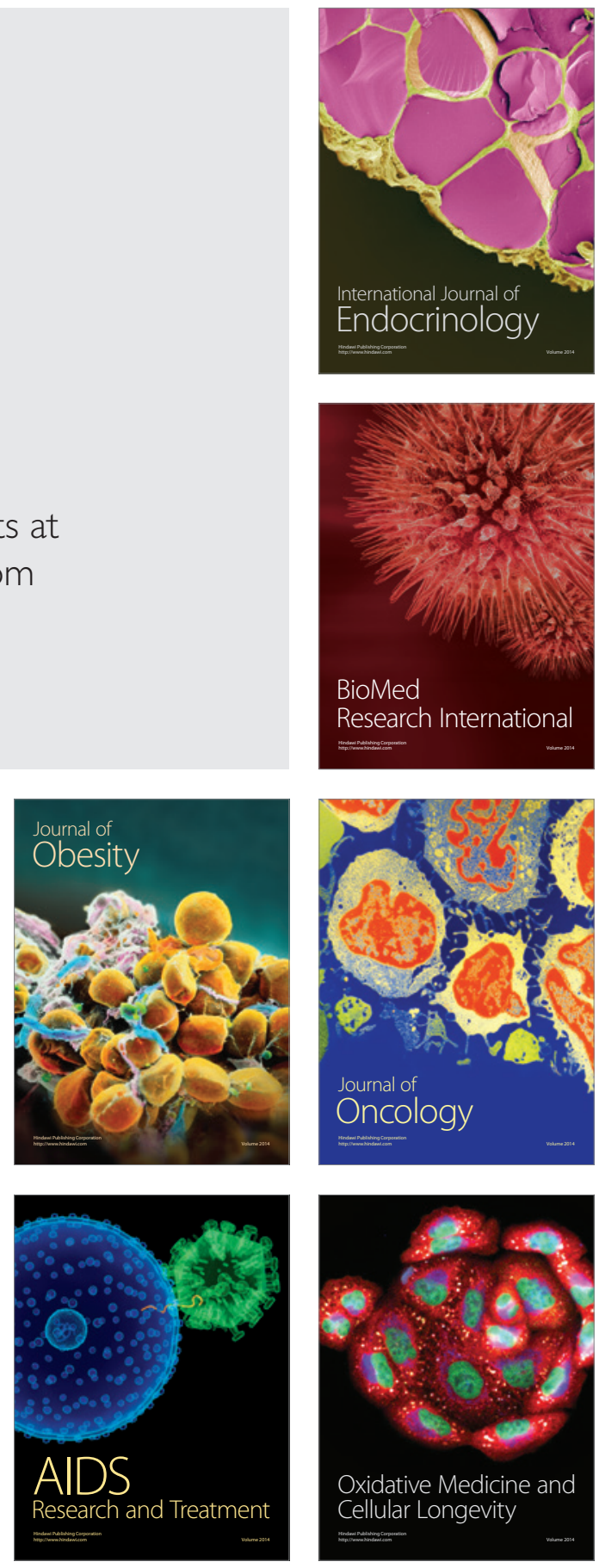